ARTICLE

Received 24 May 2016 | Accepted 16 Nov 2016 | Published 13 Dec 2016

DOI: $10.1057 /$ palcomms.2016.93

OPEN

\title{
What do postdocs need to succeed? A survey of current standing and future directions for Australian researchers
}

\author{
Margaret C. Hardy ${ }^{1}$, Adrian Carter ${ }^{2,3}$ and Nikola Bowden ${ }^{4,5}$
}

\begin{abstract}
When discussing the postdoctoral period in a researcher's life, a lack of career progression often boils down to "is it you, or is it me?" Is it a reduction in the quality of candidates, or the fact that there are now too many candidates for a rapidly shrinking pool of jobs? Australia provides an ideal case study, as a large and decentralized country with a government mandate to build the STEMM (Science, Technology, Engineering, Mathematics and Medicine) workforce. The goal of the present study was 1) to provide a baseline for postdoctoral experiences and career aspirations in Australia, and 2) to identify gaps in postdoctoral training. When undertaking a capacity building programme it is important to know where efforts should be focused. To better understand the demographic and career progression of Australia's current cohort of postdoctoral researchers, a national survey was undertaken from 2014-2015. More than 280 postdoctoral researchers from government, industry and academic institutions responded. Our results indicate that although postdoctoral researchers work more than the legal maximum of a 38-hour a week (on average) and have a long-term plan to stay in research, there is significant concern over the long-term viability of research careers due to job insecurity and a shortage of funding.
\end{abstract}

\footnotetext{
${ }^{1}$ The University of Queensland, Queensland, Australia ${ }^{2}$ Monash Institute of Cognitive and Clinical Neurosciences, Monash University, Victoria, Australia ${ }^{3}$ School of Psychological Sciences, Monash University, Victoria, Australia ${ }^{4}$ School of Medicine and Public Health, Faculty of Health \& Medicine, The University of Newcastle, New South Wales, Australia ${ }^{5}$ Hunter Medical Research Institute, New South Wales, Australia Correspondence: (e-mail: margaret. hardy@uq.edu.au)
} 


\section{Introduction}

- he role of the postdoctoral researcher (PDR) was traditionally a training period, bridging the divide between newly emerged $\mathrm{PhD}$ graduates and a permanent or tenured role in research. The postdoctoral period should be a functional, fluid, and formative period in a researcher's career (Su, 2013; Drotar et al., 2015). Previous work has demonstrated that outputs during the postdoctoral period can be affected by environmental factors (Felisberti and Sear, 2014), as well as by gender (Borrego et al., 2009). The number and duration of postdoctoral appointments also varied by discipline: a decade post- $\mathrm{PhD}$, biochemists represented the largest proportion of untenured faculty out of six mathematics-based disciplines (Nerad, 1999). In recent years the average age of a funded investigator has steadily increased, from 39 in 1980 to 51 in 2008 for the National Institute of Health in the United States; the average age of a new investigator increased from 36 to 42 over the same period (Matthews et al., 2011). The rising age of chief investigators has extended the duration of this formative training period, which has caused a seismic shift in career advancement for research scientists. Subsequently, opportunities for career progression and advancement have not kept pace with changing economic realities and priorities.

In Australia, the average age of chief investigators applying for funding from the National Health and Medical Research Council (NHMRC, the Australian equivalent to the NIH) has increased substantially in the last twenty years. In 1983, 84\% of NHMRC chief investigators were aged $30-49$, and $16 \%$ were aged $50-74$; in $2013,43 \%$ of chief investigators were aged $30-49$, and $57 \%$ were aged 50-74 (Structural review of NHMRC's grant programme consultation paper, July 2016).

In Australia, researchers spend an estimated 550 working years writing biomedical grants for the NHMRC each year (Herbert et al., 2013). When the funding agency tried to streamline the application process to reduce the burden on researchers, the average time spent writing NHMRC grants increased by 67 years, to 614 working years per annum (Barnett et al., 2015). With success rates around $15 \%$ depending on the scheme, this has a considerable impact on personal workload and family relationships (Herbert et al., 2014). The NHMRC is currently undergoing a structural review of its funding schemes through a national consultation process (NHMRC, 2016).

Increasing numbers of $\mathrm{PhD}$-qualified graduates and shrinking relative research funding (because of the exponential increase in the number of applications), have resulted in a career landscape in which researchers can be retained in an perpetual postdoctoral period: enter the "Postdocalypse" (Perlstein, 2016). Between the reality that world rankings for universities are coupled to the number of $\mathrm{PhD}$ graduates, and federal bursaries being allocated to Australian universities based on the number of $\mathrm{PhD}$ graduates each year (Australian Government, 2016), it is unlikely we will see the an end to Postdocalypse without some structural reform.

The Postdocalypse has been precipitated by a shift in the postdoctoral period from a training pathway in preparation for a permanent role to a project researcher model, and this has happened across industry, government and academic employers. Inhabitants of the Postdocalypse are characterized by a family of shared traits: productivity, with respect to writing both grants and papers (Herbert et al., 2013; Barnett et al., 2015); innovative ideas and uses for existing technologies (Packalen and Bhattacharya, 2015); and, an increase in their personal workload to fund their research (Herbert et al., 2014). For most, the goal is still to land a permanent role in research. However, few have long-term stability in their careers.

To change the trajectory of the postdoctoral position, a reevaluation of incentives and funding structures that discourage short-term positions, and encourage permanent positions, should be considered (Stephan, 2012). Previous Australian research has outlined three factors to make a postdoctoral position a more effective training period: (1) increased job security; (2) better delivery of mentoring; and, (3) reformation of funding bodies, particularly to include smaller grants and directed schemes to help primary caregivers return to the workforce (ACOLA, 2012).

In the United Kingdom, less than $0.5 \%$ of persons who have earned PhDs in Science, Technology, Engineering, Mathematics \& Medicine (STEMM) will become a professor, while 53\% leave academia for a career outside science after obtaining a PhD (The Royal Society, 2010). In New Zealand, approximately 2\% of STEMM PhD graduates reach professor, while $75 \%$ leave for careers outside science post-PhD (New Zealand Ministry of Research Science and Technology, 2010). A PhD doesn't necessarily translate into a life-long career in University research, nor should it. The postdoctoral training period, however, needs to evolve to ensure PDRs are effectively prepared for careers that make use of the high level analytical and critical thinking skills developed during the course of a $\mathrm{PhD}$, as well as developing skills in grant writing to support a career in academic research. To ensure PDRs remain competitive for jobs outside research, providing attendant skills in business development, intellectual property management, data visualization, and effective communication (among others) would be useful. Institutions should consider the goals and needs of their PDRs, and balance these components accordingly when providing training.

This manuscript aims to: (1) establish a baseline dataset of the current postdoctoral experience and career aspirations in Australia; and (2) identify gaps in training during the postdoctoral period. This analysis will provide a much needed resource for those responsible for leading, shaping, funding, facilitating, or pursuing postdoctoral positions.

\section{Methods}

The Australian Postdoctoral Reference Survey is a biennial initiative from the Early- and Mid-Career Researcher (EMCR) Forum designed to provide an overview of the environment for early- and mid-career researchers. More information on the Australian Postdoctoral Reference Survey is available on the Forum website: https://www.science.org.au/supporting-science/early-and-midcareer-researchers/emcr-forum. This study adheres to the Guidelines of the ethical review process of The University of Queensland and the National Statement on Ethical Conduct in Human Research (Approval Number 2014001072). The pilot study ran from 13 October 2013 to 23 June 2014, and had 945 respondents. The survey was accessible online, from 23 October 2014 to 23 May 2015, and 284

EMCRs in Australia responded. Data were normalized by gender by using the total number of men as $100 \%$ and the total number of women as $100 \%$, and adjusting the total number of question responses in a category out of $100 \%$ for each gender.

\section{Statistics}

A list of questions used in a statically supported comparison is provided (Table 1). Values were compared by the gender of the respondent in GraphPad Prism (Version 7.0a), using a two-way ANOVA with a Tukey's post-test for multiple comparisons (family-wise significance $\alpha=0.05$ ). Means were compared across rows and columns. Statistically significant differences are noted in the results if present.

\section{Demographics}

Participants were recruited from a list of over 3,000 individuals who had signed up to the Australian Academy of Science EMCR Forum that represents postdoctoral researchers in STEMM disciplines. A total of 284 postdoctoral researchers participated in the survey, approximately $5 \%$ of the estimated 6,000 postdoctoral researchers employed in Australia (Australian Academy of Science, personal communication). The respondents accurately represented the diversity of backgrounds represented by Australian postdoctoral researchers (Table 2). More women 
Table 1 | The survey questions used in the statistical analysis

\begin{tabular}{ll} 
Number & Question \\
\hline 1 & Your primary research discipline \\
$2^{\star}$ & How many hours per week do you actually work on average? \\
3 & What would be the main reason you would consider leaving a career in research? \\
4 & How confident do you feel that your career aims will be fulfilled? \\
5 & I believe Australian researchers need to work overseas in order to be considered competitive for funding and promotion opportunities. \\
6 & To what extent do you feel you have developed new research skills during your postdoctoral position(s)? \\
7 & With regard to promotion to the next salary level in your current position, how important is teaching? \\
$8^{\star}$ & How important do you personally consider teaching for a postdoctoral position? \\
$9^{\star}$ & How important do you personally consider training a research higher degree (RHD) student as part of a postdoctoral position? \\
10 & How useful have internal technical training courses been? \\
11 & How useful have external technical training courses been?
\end{tabular}

Values were compared by the gender of the respondent in GraphPad Prism (Version 7.0a), using a two-way ANOVA with a Tukey's post-test for multiple comparisons ( $\alpha=0.05)$. Means were compared across rows and columns. Questions that returned statistically significant differences are noted with an asterisk $\left(^{\star}\right)$.

than men participated (62\% women and $38 \%$ men), no respondents identified as outside that gender binary, and the majority of respondents were in their early 30s (31-35 years, $40 \%$ ), followed by late twenties and late thirties (22\% each).

Nearly $80 \%$ of respondents were within 10 years post-PhD (25 years post- $\mathrm{PhD}, 50 \%$; 6-10 years post- $\mathrm{PhD}, 29 \%)$. Approximately equal numbers of respondents have worked as a postdoctoral researcher for $2-3,3-5$, or $6-10$ years (26\%), and more than $80 \%$ had a current contract of less than 3 years' duration ( $\leq 1$ year, $40 \%$; 2 years, $15 \%$; 3 years, $27 \%$ ).

Approximately $80 \%$ of participants were from STEMM fields (science, technology, engineering, mathematics, and medicine). The majority came from the life sciences (61\%), with approximately equal numbers from physical sciences and engineering, and health sciences (16 and 18\%, respectively). The remainder represented social sciences and humanities, including $0.7 \%$ who listed "other". There were no statistically significant differences in the scientific discipline reported between men and women respondents.

\section{Career aims and aspirations}

Over half (52\%) stated the primary reason for starting a postdoctoral position was as a stepping-stone to a full-time research career (Fig. 1), with respondents split between wishing to continue working on a topic they enjoyed during their $\mathrm{PhD}(22 \%)$ and working with a research team they respected and admired (20\%). Slightly more than half of respondents thought they were likely to be personally able to fulfil their career aim (54\%), and there were no statistically significant differences between men and women in this response.

Despite most researchers taking postdoctoral positions in order to develop a medium- or long-term career in research (28 and $54 \%$, respectively), the majority of respondents do not think this will be possible because of structural (rather than personal) challenges. This is primarily due to inadequate job security (for example, short-term contracts) and a lack of funding (37\% for each), lack of independent positions available (14\%) and family or career responsibilities (6\%). When data are normalized by gender, approximately equal numbers of respondents are discouraged by a lack of funding (36.3\% of men, and $41.8 \%$ of women) and a lack of job security ( $40.2 \%$ of men, and $38.2 \%$ of women). Men were slightly, but non-significantly more likely to consider leaving a career in research because of family or carer responsibilities $(7.8 \%$ of men, and $5.5 \%$ of women).

More than half of respondents (57\%) believed that Australian researchers had to work overseas to be considered competitive for funding and promotion opportunities; there were no statistically significant differences between men and women in this response. Further to this, more than half $(55 \%)$ of respondents have considered moving their research programme overseas.

\section{Career development}

More than $80 \%$ of respondents felt they had somewhat or significantly developed new research skills during their postdoctoral position(s); there was no statistically significant difference in reporting between men and women. In a multiple-option response, more than $70 \%$ developed these skills through selfdirected learning, $48 \%$ by working with their peers, and about $33 \%$ each by working with other senior scientists in their laboratory or directly with their supervisor. There were no significant differences in the usefulness of external compared to internal technical training programs between men and women or responses from 1 (not at all) to 7 (significantly). The data suggest that an individual's success may have more to do with the proficiency of PDRs and access to senior scientist in their group, rather than the quality of internal and external training programs.

At the start of their postdoctoral position, 54\% reported having an informal career development plan (for example, a discussion with their supervisor) and a further $10 \%$ had a formal written plan, while $35 \%$ had no plan. This is particularly concerning, both at an individual and institutional level.

More than $75 \%$ of respondents report having no or few opportunities to undertake work experience placements, internships, or sabbaticals with other institutions to upskill. In an environment with increasing emphasis on collaboration with industry and across disciplines, support for these short-term training initiatives could yield significant improvements in the research career pathway and post- $\mathrm{PhD}$ career prospects.

\section{Networking and mentoring}

For more than half of the respondents, the supervisor filled the role of mentor (someone who supports long-term development and goals). Informal mentoring within the organization (20\%) and a formal mentoring programme (14\%) were also common, while a troubling $23 \%$ reported having no mentor at all. Formalized reporting on mentoring would allow institutions to address the need for postdoctoral researcher mentoring.

More than $65 \%$ of respondents reported support for networking by encouraging attendance and presentations at internal meetings or seminars, and $80 \%$ of respondents reported that their institution provides support to attend a conference or meeting subject to funding and/or supervisor's approval. 


\section{Table 2 | An overview of the demographics of the respondents $(n=284)$}

Number

Percent

Current Position

Research Officer

Postdoctoral Fellow

Junior Research Manager ( $<5$ staff and students)

Senior Research Manager ( $>5$ staff and students)

Other

Total

\section{8}

Employer

University, teaching position

University, research position

University, combined teaching and research position

Government research institute (for example, CSIRO, ANTSO)

Research institute

Private company

Other

Total

Gender

Man

Woman

Other

Total

Age

$<25$

25-30

$31-35$

36-40

$41-45$

$>45$

Total

Number of years since completion of highest degree

0 (never been a postdoc)

$0-1$

$2-3$

3-5

6-10

11-15

$16-20$

$>20$

Total

What is the duration of your current contract?

$<1$ year

2 years

3 years

3-5 years

$>5$ years

Permanent position

Other

Total

What is your primary research discipline?

Physical Sciences \& Engineering

Life Sciences

Health Sciences

Social Sciences and Humanities

Other

Total
146

17

6

17

254

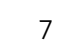

134

17

14

37

4
70

283

107

177

284

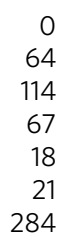

284

26.8

57.5

6.7

2.4

6.7

100.1

2.5

47.3

6

4.9

13.1

1.4

24.7

99.9

37.7

62.3

0

100.0

0

22.5

40.1

23.8

6.3

7.4

100.1

$\begin{array}{rc}5 & \\ 43 & 1.8 \\ 72 & 15.2 \\ 77 & 25.5 \\ 72 & 27.3 \\ 9 & 25.5 \\ 4 & 3.2 \\ 0 & 1.4 \\ 282 & 0 \\ & 99.9\end{array}$

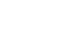

99.9

107

39.9

14.6

26.5

11.9

0.7

3

3.4

100.0

268

16.2

61.3

18.7

3.2

0.7

100.1

\section{Publishing and applying for funding}

Funding is the primary concern for many postdoctoral researchers (see Career Aims and Aspirations). Internal working groups (IWG) are used to review and provide feedback on confidential aspects of research, including funding applications and publications. Only $17 \%$ of institutions offer an IWG to provide feedback on publications, compared with $75 \%$ that offer an IWG for funding applications (including for grants, fellowships, and other 
funding applications). In total, $54 \%$ of respondents thought an IWG for publications would be useful (19\% did not agree, and $27 \%$ were unsure).

Nearly $90 \%$ of respondents report routinely receiving emails about funding opportunities from their organization or the major national funding bodies (the Australian Research Council or NHMRC), indicating this is a common (but not necessarily effective way) to advertise funding and grant opportunities to early-career researchers. Only $64 \%$ reported being aware of fieldspecific opportunities (including fellowships and travel bursaries), and $28 \%$ were aware of special interest support groups at their institution. Increased outreach is needed in these spaces.

The quality of publications is also a key component of career advancement. Only $27 \%$ received guidance about predatory publishers from supervisors, mentors, or institutes. Increased education in this space could prove beneficial. While $25 \%$ of respondents reported being encouraged to publish in open-access journals, $46 \%$ were not and a further $29 \%$ were unsure.

The bulk of institutes provided clear guidelines for ethics, ethical data analysis, and ethical publication writing (55\% yes, $24 \%$ no, $21 \%$ unsure). More than $70 \%$ of respondents reported being encouraged to consider experimental design with an eye towards results that lead to publications or other measureable metrics (for example, patents), with roughly equal proportions reporting no $(16 \%)$ or being unsure (14\%).

\section{Teaching and supervision}

Survey participants highlighted the disparity between the expectation that teaching and supervision is a minor part of the postdoctoral training period, and the importance of these roles in a well-functioning research ecosystem.

In Australia, postdoctoral appointments are often indicated as either teaching-focused or research-focused, with different attendant expectations for the teaching and research. Respondents were asked whether teaching was important for promotion (Fig. 1a) or to them personally (Fig. 1b). Teaching was seen as somewhat important for promotion and to respondents personally, but where the respondents felt most strongly was in the personal importance of training and mentoring RHD students (Fig. 1c).
More than $40 \%$ of respondents reported being supported in mentoring or supervising Honours and research higher degree students (RHD, including $\mathrm{PhD}$ and Masters), while $20 \%$ were not supported (Fig. 2). The remainder were either somewhat (30\%) or unsure (8\%) about their levels of support.

When the percent of respondents was normalized by gender, there was only one significant difference in the responses between men and women when asked how important teaching was for promotion: more men responded 1 (irrelevant) than women responded 7 (critical).

When asked "How important do you personally consider teaching for a postdoctoral position?" there were no significant differences in the responses of men and women when the percentages were normalized by gender.

Significant differences in the responses between men and women were also noted when asked, "How important do you personally consider training an RHD student as part of a postdoctoral position?" On a linear scale of 1 (irrelevant) to 7 (critical), a statistically significant proportion of women selected 7 compared to the number of men and women who selected 1, 2, or $3(\alpha=0.05)$. In brief, the majority of both men and women think training RHD students is a critical part of the postdoctoral role.

A robust training programme for new researchers is an area of key importance for many institutional metrics (including the time to degree completion, and number of international and domestic graduates), and this duty often falls to postdoctoral researchers. The data reflect a considerable discrepancy in the relatively low perceived weight given to RHD training during hiring and promotion, compared to the critical importance postdoctoral researchers assign to RHD training as part of their role. Ensuring these staff are supported in their efforts to improve RHD student education should be a clear priority, which is reflected in hiring and promotion practices institutionally.

\section{Outreach and engagement}

One of the three main messages from a 2013 pilot study was the desire for more training and opportunities for outreach and engagement work (Hardy, 2014). In addition to building important effective communication skills, talking with the public and the media can bring new collaborators and funders into the project (Lyall et al., 2013).

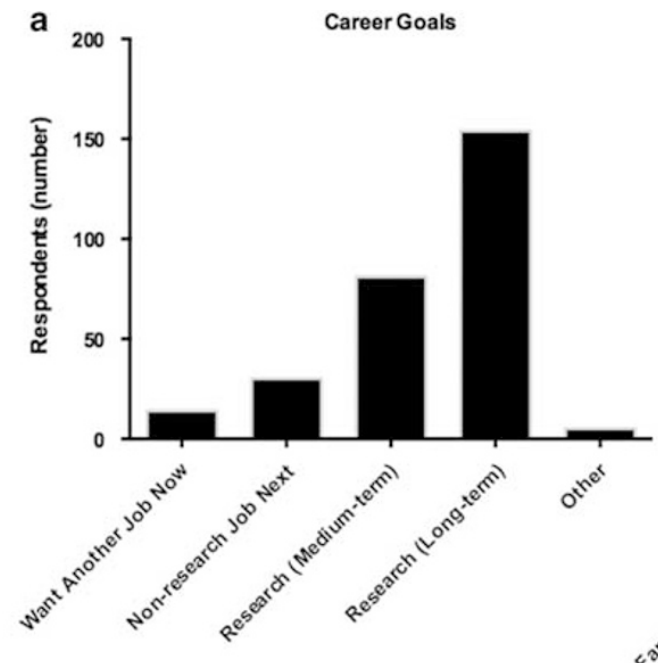

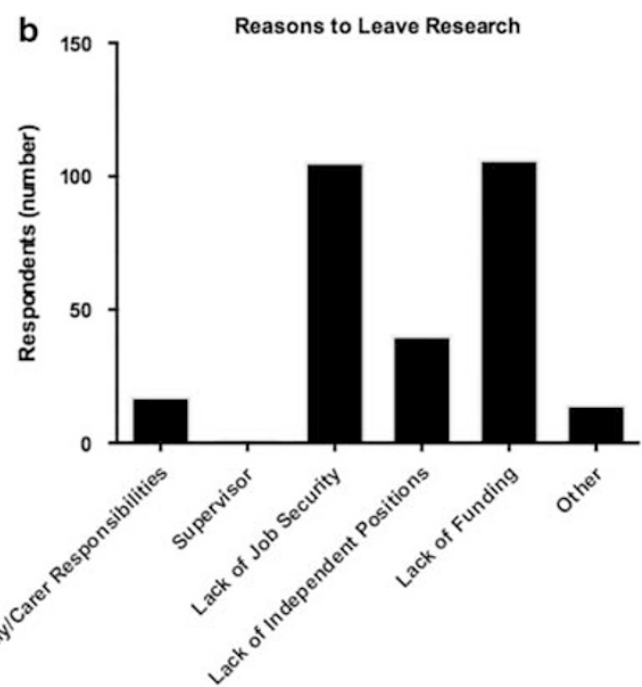

Figure 1 | Australian postdoctoral researchers would like to stay in research careers, but a number of reasons to leave research careers cause roadblocks. More than $\mathbf{8 0 \%}$ of respondents would like to stay in research in the medium- or long-term, and $16 \%$ would prefer a career outside research in the immediate or near future (a). The primary reasons to leave careers in research (both at $37 \%$ ) were a lack of job security and a shortage of funding (b). 
a

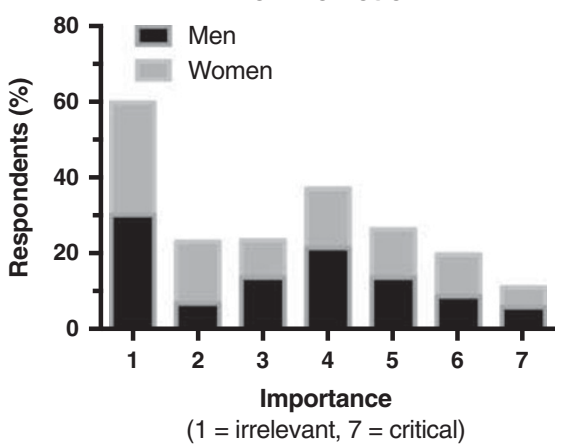

b

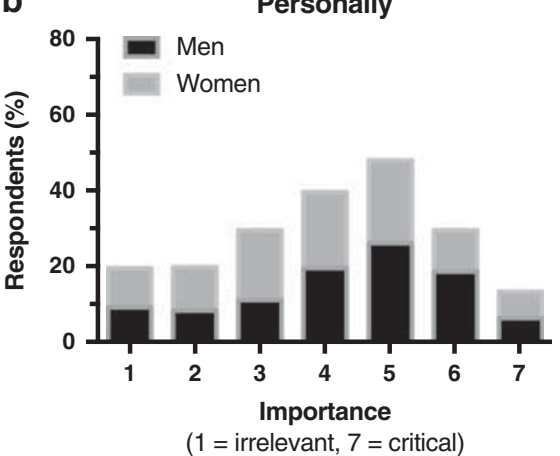

C

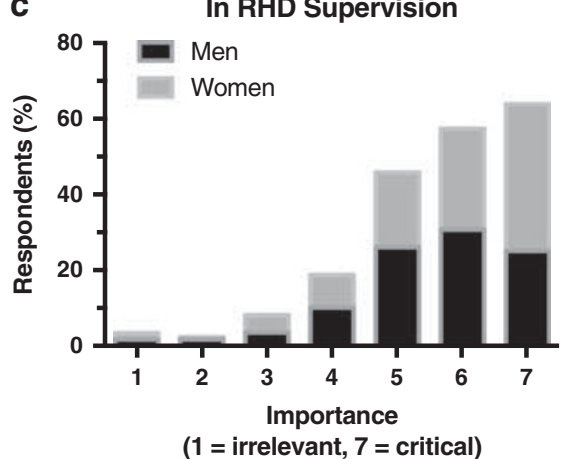

Figure 2 | Teaching is an important contribution made by most Australian postdoctoral researchers, although it is not perceived as high-value for promotion. Respondents rated how important teaching was on a scale of 1 (unimportant) to 7 (important) for promotion (left); to them personally (centre); and, in training and supervising RHD students (for example, PhD and Masters students) (right).

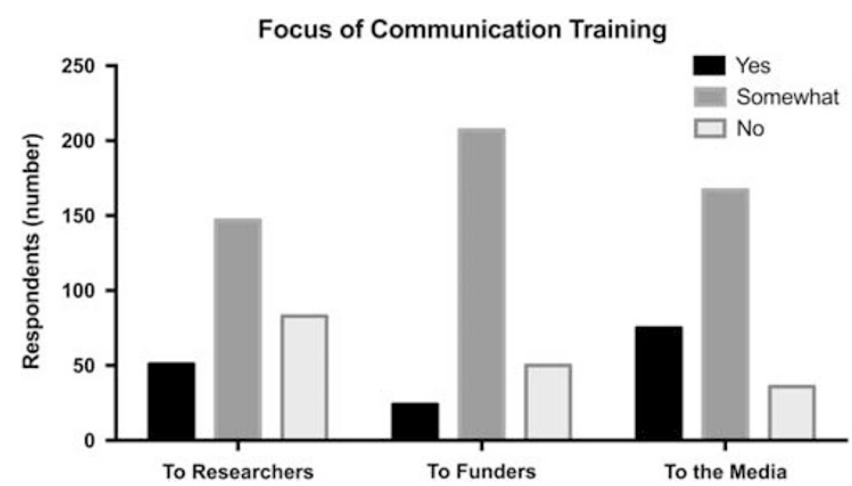

Figure 3 | Targeted communication training can make a valuable contribution to career progression for postdoctoral researchers. Training that is specific for improving communication with other members of the research community (left), with funders or potential funders (centre) and with the media (right) was examined.

Most institutes offered training in how to talk with other researchers, funders, and to the media (Fig. 3). The largest focus of effective communication is to the media (for which $27 \%$ of respondents received training), followed by training for communication with the research community (18\%), and potential funders $(9 \%)$.

Of the $94 \%$ of respondents that conduct research funded by wholly or in part by industry, only $9 \%$ report being introduced to existing industry contacts (for example, by being included in client meetings and visits to client sites). The remaining respondents were unsure $(40 \%)$ or were not included $(45 \%)$. Only $20 \%$ of postdocs were encouraged to present directly to clients or funding partners; $27 \%$ were actively discouraged while $45 \%$ were unsure. This lack of experience in how to talk and network with funding partners is a critical hindrance to building an independent research career outside academia, particularly with the limited number of industry partners available in Australia.

\section{Working conditions}

Research institutes vary in how transparently they communicate expectations for working conditions. Salary rates are made publically available at more than half of the institutions represented (yes, 64\%; no, 17\%; unsure, 19\%). Only 38\% of respondents thought the path for promotion was clear at their institution (no, $48 \%$; unsure, $14 \%$ ). More than half of the survey

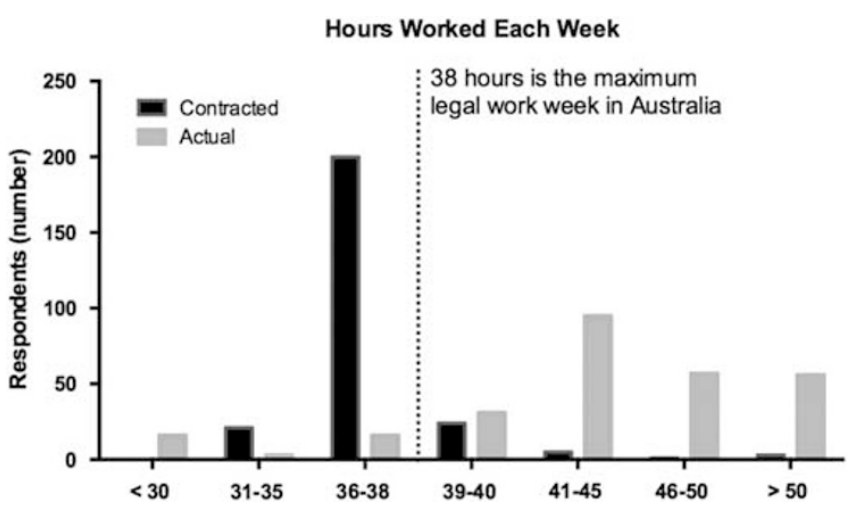

Figure 4 | A comparison of the number of hours Australian postdoctoral researchers are contracted to work, and the actual number of hours in an average work week. Although $96 \%$ of postdoctoral researchers are contracted to work 36-38 hours (black bars), more than $75 \%$ work more than 41 hours each week (gray bars). Note 38 hours (the dashed line) is the legal maximum length for a work week in Australia.

participants have to provide their own funding (e.g., through grants or competitive fellowships) in order to be eligible for promotion (yes, $53 \%$; no, $14 \%$; unsure, $32 \%$ ).

The number of women respondents who reported working 4145 hours a week was statistically greater than the number of men who report working $<30,31-35$, or $36-38$ hours each week. The number of women who work 41-45 hours each week was statistically greater than the number of women who work 3135 hours each week.

Although $96 \%$ of respondents were contracted to work 3140 hours ( 38 hours is the legal maximum work week in Australia, according to the Australian Government Fair Work Ombudsman), more than $75 \%$ work more than 41 hours-including $20 \%$ who report working more than 50 hours each week (Fig. 4). Consequently, $39 \%$ of the research hours in Australia conducted by $\mathrm{PhD}$-qualified postdoctoral researchers are contributed for free, as unpaid overtime. This is in contrast to other professionals with similar levels of training, for example medical doctors and solicitors, who are billed by the hour and paid penalty rates for overtime.

\section{Limitations}

The total number of postdoctoral researchers in Australia is estimated to be around 6,000 in government, industry, and 
academic research roles. The respondents represent roughly $10 \%$ of the 3,000-member listserve used to recruit participants, and a number of participants likely found their way to the survey via social media or institutional emails. However, given that many postdoctoral researchers change roles and then email addresses within a year, there's a good chance the listserve is almost always out of date. While a quantitative survey allows analysis of a large number of respondents, a mixed methods approach that employed qualitative analysis of postdoctoral researchers views may provide a richer understanding of the reasons and motivations behind respondents responses.

As with any volunteer survey, respondents may have been selfselecting for certain disciplines or personal circumstances (for example, respondents are $\mathrm{PhD}$-qualified researchers who have chosen a postdoctoral position, which was traditionally considered a pathway to a long-term career in research).

The study was designed to gauge the current standing and future directions needed to support STEMM fields, and as $80 \%$ of respondents identified from within those fields. Additional work with questions tailored to the social sciences and humanities, perhaps through their learned academies, would provide a useful comparison in the future. Women comprised a greater representation of respondents (60\%) than men (40\%), which is notable given that most Australian researchers above Level A (or its equivalent) are male (Bell, 2009). An additional limitation with respect to training is that the survey only asked for the presence or absence of training opportunities and programs, and did not have the scope to evaluate the outcomes or efficacy of the programs and their contributions to career progression.

\section{Recommendations}

A variety of topics were covered in the survey, and a brief summary of the findings and policy recommendations from each section follows.

Career aims and aspirations. More than $80 \%$ of respondents want to have a career in research over the medium- to long-term, and more than $50 \%$ of the respondents stated the primary reason for starting a postdoctoral position was as a stepping-stone to a full-time research career. A lack of job security and a lack of funding (37\% for each) stand in the way of those goals. Nearly $60 \%$ believe Australian researchers had to have overseas experience to be competitive for funding and promotion, and $55 \%$ have considered moving their research programme overseas. As the funding wanes and waxes in Australia, we should be aware there are other countries who are very willing to hire our technically proficient and highly skilled future leaders. In addition, without a strategic plan for research funding that the major funding bodies have agreed to, it is a challenge for researchers to plan their career in a way that maximizes the potential of funding success longterm.

Career development. More than $80 \%$ of respondents reported somewhat or significantly developing new research skills during their position, and the most cited sources for skills development were self-directed learning (70\%), working with peers (48\%), and working with senior scientists or their supervisor (33\%). About $65 \%$ of respondents had either an informal or a formal discussion about their career plan, and $75 \%$ report having few or no opportunities to undertake work experience or other opportunities to upskill. This emphasizes institutional barriers to access, and suggests an exchange programme between institutes that contain similar disciplines could be developed, similar to the NHMRC TRIP Fellowship. In addition, this highlights the need for supervisors and senior scientists to be available to their laboratory members, and not overburdened with grant writing or administrative duties.

Networking and mentoring. More than 20\% of respondents reported the total lack of a mentor, through either formal or informal channels. Although the idea of a mentor and what that relationship entails varies by field, the goal of using a mentor as an advocate and springboard to a wider network in the scientific community should transcend disciplinary boundaries. Ethical considerations of the mentor-mentee relationship should be made clear from the beginning, and in some cases a mentor can be an advocate for an early-career researcher who is experiencing harassment or pressure to act unethically. As recent examples have shown, a mentor can play a critical role in scientific fraud (Fanelli, 2009).

Publishing and applying for funding. All researchers, even at the beginning of the career pathway, understood that to be hired and promoted required publication of peer-reviewed articles and a track record of research funding. Like any technical writing, these are skills that require time to develop-time postdoctoral researchers often are not afforded in short duration contracts. Further, funding bodies often require that the applicant holds a funded position to be eligible for research grant rounds, which places a unique burden on postdoctoral researchers. For an ecosystem that runs on high-impact publications, it is perhaps unsurprising that $55 \%$ of researchers work at institutions that provide clear guidelines for ethical conduct in published research, and $70 \%$ are encouraged to consider publication or measurable metrics like patents when designing experiments. However, only $27 \%$ received guidance about predatory publishing. In an era of "publish or perish", postdoctoral researchers are trapped behind a mountain of unpublished data and high publication fees some open-access and some high-impact journals. Dissemination and engagement are becoming buzzwords for people responsible for allocating funding, so support should be provided for the best homes to be found for our research.

Teaching and supervision. Figure 1 illustrates the discrepancy in how much postdocs value teaching and supervision, compared to how much it contributes to promotion and to the quality of RHD student experiences. Postdocs are the front line of supervision for RHD students, but often are omitted from formal agreements that assign supervisory duty. A "supervisor audit" could help identify those postdocs who have been particularly active and involved mentors, and perhaps an informal "technical advice" category or similar could be formally added to the advisory team structure. This would be particularly useful for technical staff or people responsible for individual instruments or teaching techniques. That enables postdocs to continue to do work they are well-suited to and qualified to do, while adding ways to illustrate technical proficiency on their resume and to their supervisor.

Outreach and engagement. Although 94\% of respondents conduct research that is wholly or partially funded by industry, only $9 \%$ report being introduced to those industry funders. Support for researchers to grow their networks with industry partners (including NGO and government bodies, as appropriate) should be provided, possibly in conjunction with conferences or state-based advocacy groups like Life Sciences Queensland (http://www.lsq. com.au/). Certain regions require more funding than others to meet these goals, for example our second-largest state, Queensland. Queensland is a state 2.5 times the size of Texas, and has the third largest population of any state or territory in Australia, not considering the Australian Antarctic Territory. 
The quality and type of outreach and engagement activities should be reviewed on an institutional basis, and should be modular so training can be tailored to the goals of each postdoctoral researcher. On completion of a training programme participants should be formally recognized, as it then becomes a $\mathrm{CV}$-worthy bullet point. Clear aims and outcomes from engagement work should also be evaluated, and definitions for "impact" and "engagement" standardized across institutions and by funding bodies to ensure researchers know on what they will be evaluated.

Working Conditions. Around $75 \%$ of respondents work more than 41 hours each week, including $20 \%$ who work more than 50 hours each week. The amount of unpaid labour contributed to the science economy by postdoctoral researchers should be evaluated by individual institutions, and the option of flexible work conditions (especially for time-sensitive experiments) should be considered. For short-term contracts that are less than a certain duration (for example, 3 months), the possibility of employing postdoctoral researchers through a central fund as hourly contractors entitled to penalty rates could be considered. Implications of short-term contracts and long hours outside the normal work week should be considered from an equity perspective also, as it acts as a deterrent to those who hope to return to research after a career interruption or who have primary caregiving responsibilities.

Equity and diversity. The pathway to a more diverse workforce that includes more researchers from traditionally underrepresented groups is to hire and retain more persons who identify in those ways.

\section{Conclusions}

Many institutions that employ postdoctoral researchers think that improving training programs will help with career progression. This is possibly the case for individuals who hope to move out of research into another career. But for the vast majority of respondents who hope to stay in a career in research, reinvesting in novel ways to increase job security (like limiting the duration of short-term contracts) and increased opportunities for smaller pots of funding that can be obtained independently would be of more use. These issues are structural, as evidenced by the agreement of respondents who represent a diverse demographic, rather than being localized to a single region or discipline. And the problems are not restricted to academic jobs: individuals across sectors work as project-based contractors in a variety of research roles, without a clear path into a permanent position.

The survey results illustrate that many postdocs are so desperate for a career in research that they are willing to sacrifice job security and work more than they are legally allowed to meet their goals. While some would respond "that's how it's was in my day", we would respectfully suggest that in your day the average age of a chief investigator was 30-50, not 50-70, and the grant success rate was not below $10 \%$. Dwelling on past models of research funding and career progression do us no favors now, in an era of global collaboration and an increased emphasis on innovation and enterprise.

To enact real change in making Australian research a sustainable career, support from the federal funding bodies would have a considerable impact. Postdocs who are regularly employed on contracts of 3 months or less could perhaps apply to a separate fund from the federal bodies for a 6-month or 1-year extension, to continue working on a project that has already been funded. This would be an effective way to continue work that has already received funding, while exploring new directions that could provide additional support for the research programme. Research is not a seasonal job, and to approach these challenges intelligently and effectively we should look to effective ways to help solve our problems. If we remove the burden of having to constantly worry about an end to a cycle of short-term contracts and constantly attend training sessions in the event we find ourselves cut off from laboratory-based research, perhaps the desired outcome of increasing innovation will occur organically.

This survey highlights the need for consistent monitoring of working conditions, reflection on the quality and quantity of training and professional development opportunities, and the creation of stable funding sources to support the future leaders of Australia's research community. Most postdoctoral researchers want a long-term career in research and believe they can achieve that aim, with sustained funding and increased job security.

Scientific training programs should recognize that a large proportion of their students and postdoctoral researchers may not continue in academic careers, despite the majority of survey respondents indicating they would like to have a long-term career in research. In the United Kingdom, 53\% of researchers leave the academic track directly after completing a $\mathrm{PhD}$ in a STEM field; in New Zealand, the number who leave is $75 \%$ (The Royal Society, 2010; New Zealand Ministry of Research Science and Technology, 2010). The findings of this report emphasize the need to diversify training programs to ensure the next generation of scientists have opportunities in industry, business, government and non-profit roles.

\section{References}

ACOLA. (2012) Career Support for Researchers: understanding needs and developing a best practice approach, Canberra, Australia, http://www.acola. org.au/PDF/CareerSupportForResearchers.pdf, accessed 17 February 2016].

Australian Government. (2016) National Innovation \& Science Agenda: Engagement and Impact Assessment Consultation Paper, Canberra, Australia, http:// www.arc.gov.au/sites/default/files/filedepot/Public/ARC/consultation_papers/ ARC_Engagement_and_Impact_Consultation_Paper.pdf.

Barnett A.G. et al (2015) The impact of a streamlined funding application process on application time: two cross-sectional surveys of Australian researchers. BMJ Open; 5 (1): e006912.

Bell S. (2009) Women in Science in Australia: Maximising Productivity, Diversity and Innovation; Canberra, Australia.

Borrego Á. et al (2009) Scientific output and impact of postdoctoral scientists: a gender perspective. Scientometrics; 83 (1): 93-101.

Drotar D. et al (2015) Competency-based postdoctoral research training for clinical psychologists: An example and implications. Training and Education in Professional Psychology; 9 (2): 92-98.

Fanelli D. (2009) How many scientists fabricate and falsify research? A systematic review and meta-analysis of survey data. PLOS ONE; 4 (5): e5738.

Felisberti F.M. and Sear R. (2014) Postdoctoral researchers in the UK: A snapshot at factors affecting their research output V. Larivière, ed. PLOS ONE; 9 (4): e93890.

Hardy MC (2014) 2013 Australian Postdoctoral Reference Survey Summary: Enhancing Planning, Development, and Communication; Canberra, Australia.

Hardy MC (2016) PDRSurveyData.xlsx. figshare, https://figshare.com/articles/ PDRSurveyData_xlsx/4012443/1, accessed 13 October 2016.

Herbert D.L. et al (2013) On the time spent preparing grant proposals: an observational study of Australian researchers. BMJ Open; 3 (5): e002800-e002800.

Herbert D.L. et al (2014) The impact of funding deadlines on personal workloads, stress and family relationships: a qualitative study of Australian researchers BMJ Open; 4 (3)pp e004462-e004462.

Lyall C. et al (2013) The role of funding agencies in creating interdisciplinary knowledge. Science and Public Policy; 40 (1): 62-71.

Matthews K.R.W. et al (2011) The aging of biomedical research in the United States G. Germano, ed. PLOS ONE; 6 (12): e29738.

Nerad M. (1999) Postdoctoral patterns, career advancement, and problems. Science; 285 (5433): 1533-1535.

New Zealand Ministry of Research Science and Technology. (2010) Igniting Potential: New Zealand's Science and Innovation Pathway. New Zealand Ministry of Research Science and Technology: Wellington, New Zealand.

NHMRC. (2016) Structural Review of NHMRC's Grant Program. NHMRC: Canberra, Australia. 
Packalen M. and Bhattacharya J. (2015) Working Paper 20920: Age and the trying out of new ideas, Cambridge, MA, http://www.nber.org/papers/w20920.pdf, accessed 17 February 2016.

Perlstein EO (2016) Postdocalypse now. [Personal Blog], http://www.nature.com/ news/young-scientists-ditch-postdocs-for-biotech-start-ups-1.20912, 1 November 2016.

Stephan P. (2012) Research Efficiency: perverse incentives. Nature; 484 (7392): 29-31.

Su X. (2013) The impacts of postdoctoral training on scientists' academic employment. The Journal of Higher Education; 84 (2): 239-265.

The Royal Society. (2010) The Scientific Century: securing our future prosperity. The Royal Society: London.

\section{Data availability}

The dataset generated and analyzed during the current study is available in FigShare: https://dx.doi.org/10.6084/m9.figshare.4012443.v1 (Hardy, 2016).

\section{Acknowledgements}

Dr James Tickner (CSIRO) was an integral part of the survey design and analysis of the data from the pilot survey. This article was written as part of the work of the Australian Early- and Mid-Career Researcher Forum, and we are appreciative of the insight and useful comments of our colleagues. We are grateful to the Australian Academy of Science for their support, in particular Prof Les Field (Secretary of Science Policy) and Dr Sandra Gardam (Early- and Mid-Career Researcher Project Officer).

\section{Additional information}

Competing interests: The Authors declare no competing financial interests.

Reprints and permission information is available at http://www.palgrave-journals.com/ pal/authors/rights_and_permissions.html

How to cite this article: Hardy MC, Carter A and Bowden N (2016) What do postdocs need to succeed? A survey of current standing and future directions for Australian researchers. Palgrave Communications. 2:16093 doi: 10.1057/palcomms.2016.93.

This work is licensed under a Creative Commons Attribution 4.0
International License. The images or other third party material in this
article are included in the article's Creative Commons license, unless indicated otherwise
in the credit line; if the material is not included under the Creative Commons license,
users will need to obtain permission from the license holder to reproduce the material.
To view a copy of this license, visit http://creativecommons.org/licenses/by/4.0/

